\title{
Operating mechanisms of mesoscopic perovskite solar cells through impedance spectroscopy and J-V modeling
}

Isaac Zarazúa ${ }^{a^{*}}$, Siraj. Sidhik ${ }^{b}$, TzararaLopéz-Luke ${ }^{b}$, Diego Esparza ${ }^{c}$, Elder De la Rosa $^{b^{*}}$, Juan. Reyes-Gomez ${ }^{\mathrm{a}}$,Iván Mora-Seród, and GermàGarcia-Belmonte ${ }^{\mathrm{d}}$

${ }^{a}$ Facultad de Ciencias, Universidad de Colima, Colima, Col. 28045, Mexico

${ }^{\mathrm{b}}$ Centro de Investigaciones en Optica, A.P. 1-948, Leon, Guanajuato 37150, Mexico

'UniversidadAutónoma de Zacatecas. Av. Ramón López Velarde \#801, Zacatecas, C.P. 98000, Mexico.

${ }^{\mathrm{d} I n s t i t u t e}$ of Advanced Materials (INAM), UniversitatJaume I, 12006 Castelló,Spain

Corresponding Authors:

* I. Zarazúa E-mail: zami@ucol.mx

* E. De la Rosa E-mail: elder@ cio.mx 


\section{Abstract}

Halide perovskite materials have shown to be an excellent alternative for low-cost, solution processed high-efficiency solar cells. The performance of perovskite solar cell (PSC) is highly sensitive to several aspects; the deposition conditions, the substrate, humidity and even the efficiency of solvent extraction after solution deposition. However, the physical mechanism involved in the observed changes of efficiency with different deposition conditions have not been totally elucidated yet. In this work, PSCs were fabricated by the wellknown Anti-solvent Deposition (AD) and the recently proposed Air-extraction Anti-solvent (AAD) process. Impedance analysis and $\mathrm{J}-\mathrm{V}$ curve fittings were used to understand the photogeneration, charge transport, charge recombination, and charge leakage properties of PSCs fabricated by AD and AAD process. The improvement in the morphology of perovskite film promoted by AAD method, produces an increase in light absorption, resulting in an increment of short-circuit current density from 19.86 to $21.77 \mathrm{~mA} / \mathrm{cm}^{2}$. At the same time, it reduces the recombination site density leading to an increase of open-circuit voltage from 0.957 to $0.995 \mathrm{~V}$. In addition, it reduces the interstitial defects resulting in reduced leakage current, thus enhancing the FF from 66.7 to $72.6 \%$. An overall increment in PCE of $\sim 24 \%$ from $12.7 \%$ to $15.7 \%$ was obtained by the application of AAD technique. This study would open up doors for further improvement of the device and will help to understand the physical mechanism of operation in PSCs and its relation with the deposition method 


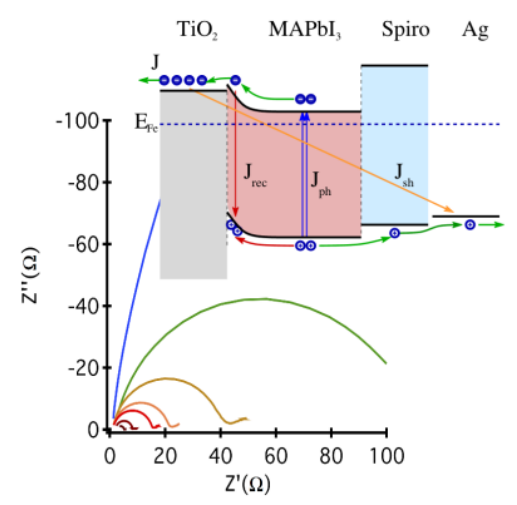

Halide perovskite solar cells (PSCs) have made a rapid stride in recent years with the maximum power conversion efficiency $(\mathrm{PCE})^{1-4}$ reaching $22.1 \%^{5,6}$, with further scope for improvement. This material shows excellent optoelectronic properties like, high absorption in the visible region, long diffusion length, and tunable optical band gap, which makes perovskite material a powerful candidate to boost the potential of photovoltaic (PV) technologies ${ }^{7,8}$. Apart from the rigorous research involved in increasing the efficiency of PSCs, the study of its physical properties, holds the key for further improvement and better understanding of this incredible material. The charge carrier mobilities in perovskite devices are comparable to the inorganic semiconductors ${ }^{9-11}$, thus showing improved charge collection efficiency at outer contacts. In addition, the high-performance of PSC is based on reduction of non-radiative bulk recombination, ${ }^{12}$ suggesting the crucial role played by the recombination processes at outer contacts.

Several methodologies have been reported to improve the efficiency of PSCs; changing the composition of perovskite material by using different organic cation $\left(\mathrm{MA}^{+}\right.$or $\left.\mathrm{FA}^{+}\right)^{13-15}$, halide ions $\left(\mathrm{I}^{-}, \mathrm{Br}^{-} \text {or } \mathrm{Cl}^{-}\right)^{16-18}$, or inorganic cation $\left(\mathrm{Cs}^{+} \text {or } \mathrm{Rb}^{+}\right)^{19-20}$, altering the architecture of the device i.e., the mesoscopic, planar or inverted configuration ${ }^{21-23}$, different deposition strategies like single step deposition ${ }^{24}$, two-step inter-diffusion ${ }^{25}$, anti- 
solvent based deposition ${ }^{26}$, vacuum-assisted deposition ${ }^{27}$ or solvent-solvent extraction ${ }^{28}$, using different electron or hole transporting materials. Although, a considerable improvement in the performance of PSCs has been obtained, a complete understanding of the physical phenomenon involved in perovskite-based PV device still remains unresolved.

Impedance spectroscopy (IS) is an excellent and well-established technique for characterizing the electrochemical systems, being particularly advantageous to extract dynamic operating parameters in a variety of solar cells technologies ${ }^{29,31}$. IS captures the current response to small-amplitude modulating voltage stimulus. In order to interpret the data generated by this method, an equivalent circuit comprising of resistive and capacitive response element is used for fitting. For correct interpretation, different elements of the circuit have to be correlated with the physical mechanism of the device. Despite its interpretative potential, the impedance response of PSCs are yet to be resolved completely as the correlation between circuit elements and physical processes is not straightforward ${ }^{32,33,36}$. However, recent studies have shown significant advances in studying the physical process occurring within the perovskite-based device. The dependence of high and low-frequency capacitance on the dielectric process and the interfacial charge accumulation within the perovskite device has been reported $36,37,42$. The high and low-frequency resistance were reported to be related to the interface between the perovskite and extraction layer and the involved recombination process ${ }^{34,37}$.

In this work, a systematic characterization and impedance analysis of PSCs fabricated by Anti-solvent Deposition (AD) and recently proposed Air-extraction Anti-solvent deposition (AAD) is reported. An increment in PCE from 12.7 to $15.7 \%$ corresponding to an increment of all the photovoltaic (PV) parameters (current density $\left(\mathrm{J}_{\mathrm{sc}}\right)$, open-circuit 
voltage $\left(\mathrm{V}_{\mathrm{oc}}\right)$ and fill factor $\left.(\mathrm{FF})\right)$ has been observed with $\mathrm{AAD}$ technique when compared to the conventional AD method. A detailed interpretation of the structural, optical, and photoelectrochemical properties was carried out to elucidate the physical processes involved in the enhancement of PV performance. It would also act as a standard for further improvement of the device. Current-voltage $(\mathrm{J}-\mathrm{V})$ curve fitting based on impedance analysis, were carried out to have a better insight into the underlying physical mechanism with the two fabrication techniques. The impedance analysis indicates that, the improvement in morphology of perovskite film fabricated by AAD technique results in a higher photogeneration current $\left(\mathrm{J}_{\mathrm{ph}}\right)$. At the same time, it reduces the recombination centers density with reduced grain boundaries due to enlarged crystals, resulting in higher open-circuit voltage $\left(\mathrm{V}_{\mathrm{oc}}\right)$. Finally, the reduced leakage current results in an enhanced FF.

Morphological, optical and electrochemical analysis. Figure 1 depicts the surficial and cross-sectional SEM images - of perovskite film fabricated by AD and AAD method and statistical distribution of the grain size of the samples is shown in Figure S1. There is a clear effect of the deposition method on surface morphology of obtained film. The film obtained by AD method (Fig 1A, S1A) presents a grain size varying from 46 to $224 \mathrm{~nm}$, with an average size of $94 \mathrm{~nm}$, while the film prepared by the AAD technique, exhibits a considerable increment in grain size varying from 108 to $869 \mathrm{~nm}$ with an average size of $234 \mathrm{~nm}$ (see Fig 1B, S1B). It is desirable to note that the thickness of perovskite film (Figure $1 \mathrm{C}$ and D) is almost unaffected by the AAD method; both of them being $200 \mathrm{~nm}$, thus neglecting its effect on the increment in absorption. 


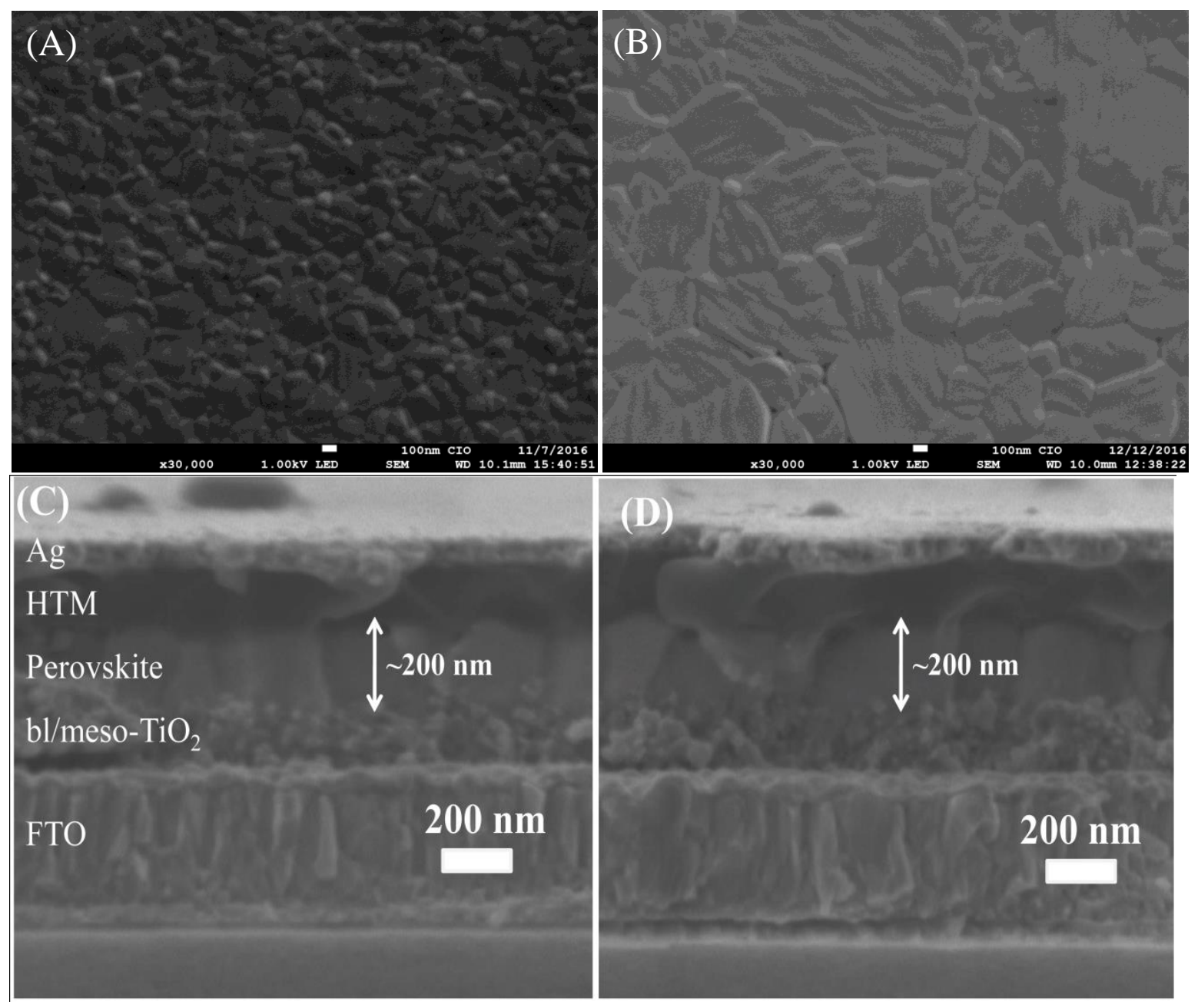

Figure 1 Top (A, B) and cross-sectional (C, D) SEM images of perovskite film fabricated by (A, C) conventional anti-solvent and $(\mathrm{B}, \mathrm{D}) \mathrm{AAD}$ process.

The absorption spectra of perovskite film fabricated by $\mathrm{AD}$ and $\mathrm{AAD}$ technique are shown in Figure 2A. Both samples are having a broad absorption band ranging from 300 to $800 \mathrm{~nm}$ with an absorption edge at $770 \mathrm{~nm}$ indicating a band gap of $1.6 \mathrm{eV}$. The use of AAD method results in an increment of absorption of around 9\%. This increment in light absorption can be attributed to the improvement in the morphology of perovskite layer. ${ }^{39-41}$

Figure 2B represents the typical reverse bias current density-voltage $(\mathrm{J}-\mathrm{V})$ curve for perovskite devices fabricated by AD and AAD methods. The average PV parameters of 15 samples and the best device of each batch are listed in Table 1, and the photovoltaic metrics 
of 15 devices fabricated using both methods are presented in Figure S2. By employing the AAD technique, an increment in average photocurrent of $\sim 10.65 \%$ from 19.62 to 21.71 $\mathrm{mA} / \mathrm{cm}^{2}$ was obtained. Also, an increment in average $\mathrm{V}_{\text {oc }}$ of $\sim 3.32 \%$ from 960 to $993 \mathrm{mV}$ and FF of $\sim 9.42 \%$ from 65.73 to $71.92 \%$ was observed. Hence, the average photoconvesion efficiency of device fabricated by AAD method increases by $\sim 25.89 \%$ in comparison with the AD sample, reaching $15.1 \%$ from $12.32 \%$. The champion cells fabricated by $\mathrm{AD}$ and AAD method provide a conversion efficiency of $13.13 \%$ and $16.40 \%$. All the photovoltaic parameters follows a similar trend as the average parameters. Forward and reverse bias scan (Figure S3) indicate that the hysteresis is considerable reduced when the AAD method is applied. 

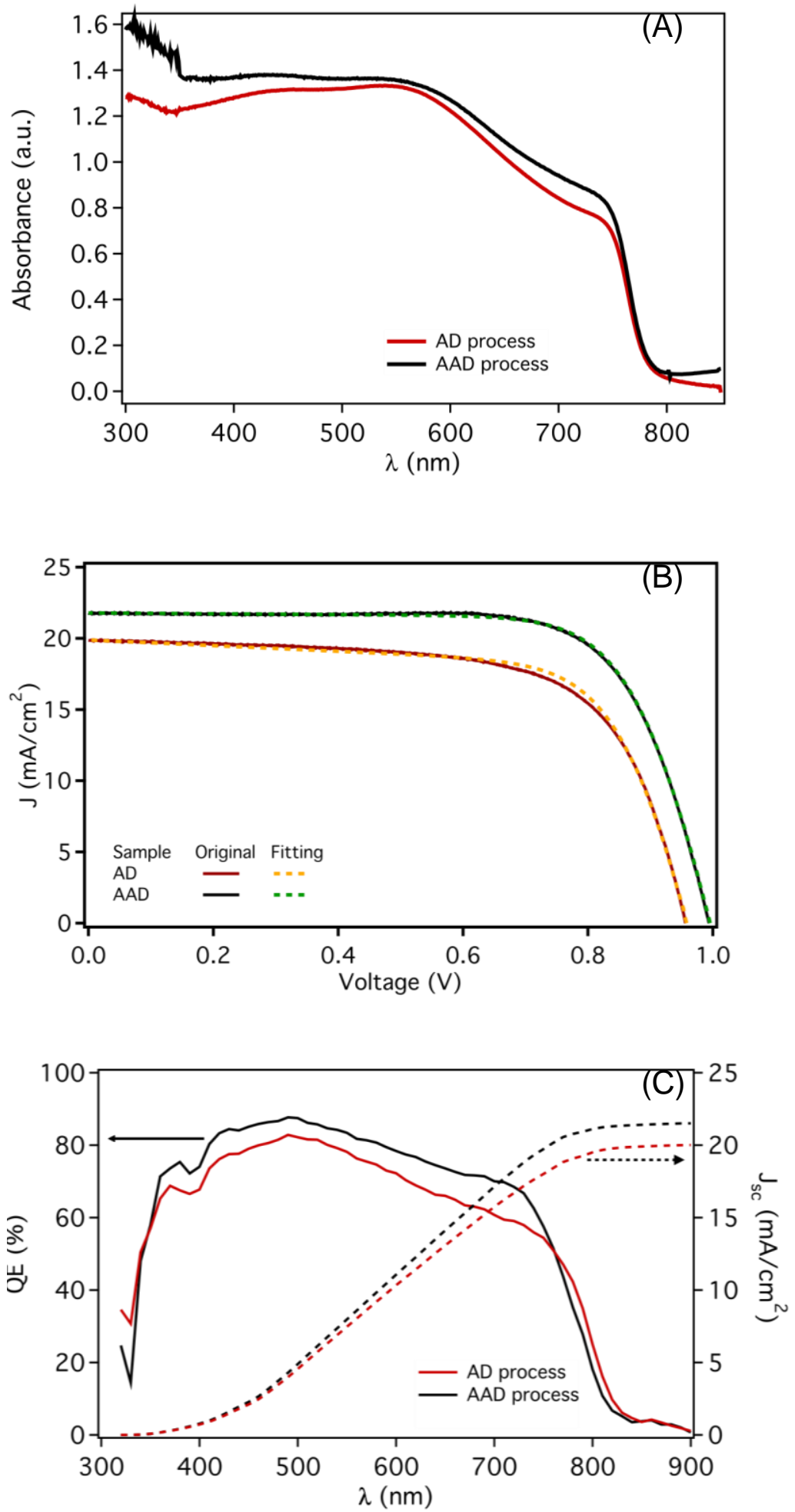

Figure 2 Optical and electrochemical measurements of the devices fabricated by AD and AAD processes, (A) Absorption spectra of the perovskite films; (B) Typical reverse bias J-V curves of PSCs with curve fitting using equation 4; and (C) Typical IPCE curves of the PSCs 
Table 1 Average PV parameters of 15 cells with the best cell fabricated by antisolvent and AAD method under uniform condition.

\begin{tabular}{|c|c|c|c|c|c|}
\hline $\begin{array}{c}\text { Deposition } \\
\text { method }\end{array}$ & & $\mathrm{J}_{\mathrm{sc}}\left(\mathrm{mA} / \mathrm{cm}^{2}\right)$ & $\mathrm{V}_{\mathrm{oc}}(\mathrm{V})$ & $\mathrm{FF}(\%)$ & $\eta(\%)$ \\
\hline \multirow[t]{2}{*}{$\mathrm{AD}$} & Average & $19.62 \pm 0.31$ & $0.960 \pm 0.01$ & $65.73 \pm 1.13$ & $12.32 \pm 0.45$ \\
\hline & Best & 20.21 & 0.968 & 67.23 & 13.15 \\
\hline \multirow[t]{2}{*}{ AAD } & Average & $21.71 \pm 0.38$ & $0.993 \pm 0.01$ & $71.92 \pm 0.94$ & $15.51 \pm 0.34$ \\
\hline & Best & 22.22 & 1.011 & 73.02 & 16.40 \\
\hline
\end{tabular}

The current density is mainly dominated by two phenomena; the photogeneration (the process where photons are absorbed to generate electron-hole pairs) and the injection (the transfer of electrons and holes to the electron and hole transport material, respectively). To understand the photogeneration in terms of contribution of each absorbed wavelength, the incident photon to current conversion efficiency (IPCE), was measured. Figure 2C shows the representative IPCE curves and the integrated current of the samples under study. The cells fabricated by AD method presents an IPCE of more than 55\% from 380 to 700 $\mathrm{nm}$, reaching a maximum of $83 \%$ at $490 \mathrm{~nm}$ and down to zero at $800 \mathrm{~nm}$. It completely matches with the absorption of perovskite material. With the use of AAD technique, an increment in IPCE of $\sim 9.6 \%$ was obtained in the wavelength ranging from 350 to $750 \mathrm{~nm}$. This increase in IPCE is the origin of the observed enhancement of photocurrent for the 
samples fabricated by AAD technique, see Figure $2 \mathrm{~B}$, integrated current in Figure $2 \mathrm{C}$ and Table 1. It suggests that, most of the increase in IPCE is due to the enhancement in light absorption, see Figure 2A.

Impedance analysis. The impedance curve in PSCs have shown to be strongly affected by the measurement conditions. ${ }^{36,3742,43}$ To simplify the analysis and to ensure a correct interpretation of the results, impedance spectra were recorded under different light intensities at open circuit condition, where the recombination process is dominant. Figure $3 \mathrm{~A}$ shows an impedance plot as a function of irradiation intensity, in which the resistive component of the two arcs shrinks as the illumination increases. The equivalent circuit shown in Figure $3 \mathrm{~B}$ was used to fit the impedance data where, $\mathrm{R}_{\mathrm{s}}$ is the series resistance due to wire and contact resistance, $\mathrm{C}_{\mathrm{g}}$ is the high-frequency capacitance interpreted as the geometric capacitance of the device; related to the dielectric properties of the perovskite ${ }^{36,42,47}, \mathrm{C}_{\mathrm{s}}$ is the low-frequency capacitance and is associated with the surface charge accumulation at the $\mathrm{TiO}_{2} /$ perovkite interface ${ }^{37,42} \cdot \mathrm{R}_{1}$ and $\mathrm{R}_{2}$ represent the low and high-frequency resistance related to the recombination process at the interface of the perovskite and the extraction, in such a way that the total recombination resistance is $\mathrm{R}_{\mathrm{rec}}=\mathrm{R}_{1}+\mathrm{R}_{2} \cdot{ }^{36,43}$ 

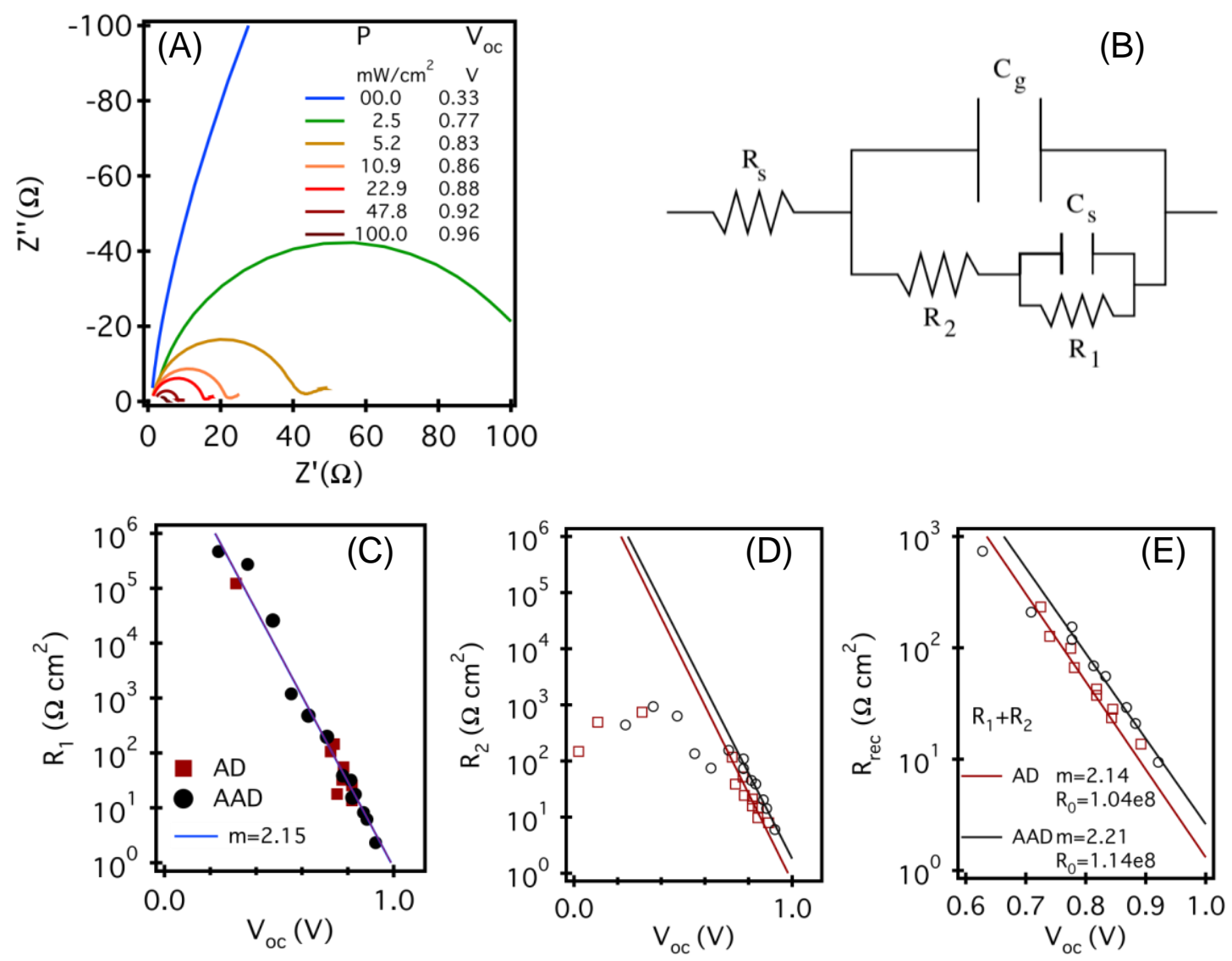

Fig 3 (A) Nyquist plot measured at open circuit conditions for different irradiation intensities corresponding to the samples fabricated by AAD process. (B) Equivalent circuit used to fit the impedance data. (C) Low-frequency resistance and (D) High-frequency resistance measured in samples made by AD method and AAD method showing the linear fit. (E) Calculated recombination resistances, with the corresponding linear fits.

According to Figure $3 \mathrm{C}$, the resistance $\mathrm{R}_{1}$ decreases exponentially with voltage and light intensity, following the expression ${ }^{36,43}$,

$$
\mathrm{R}=\mathrm{R}_{0} \exp \left(\frac{-\mathrm{qV}}{\mathrm{mk}_{\mathrm{B}} \mathrm{T}}\right)
$$

where $\mathrm{R}_{0}$ is the pre-exponential factor, $\mathrm{q}$ is the electron charge, $\mathrm{k}_{\mathrm{B}}$ is the Boltzmann constant, $\mathrm{T}$ is the temperature and $\mathrm{m}$ is the ideality factor. This behavior indicates that $\mathrm{R}_{1}$ is 
related with the non-radiative recombination process. ${ }^{36,44}$ It could be observed from Figure 3C that both kinds of samples have the same behavior, showing that the recombination process at low frequency is not affected by the AAD method.

On the other hand, the high-frequency resistance $\mathrm{R}_{2}$ (Figure 3D ) has two characteristic region, indicating two parallel processes, each one dominant at different open-circuit voltages. From 0 to $0.7 \mathrm{~V}, \mathrm{R}_{2}$ does not show a direct dependence on voltage, which further decreases for $\mathrm{V}_{\mathrm{oc}}>0.4 \mathrm{~V}$. According to the literature, FF of PSC is dominated by the leakage process in this range of voltage and is characterized by a constant resistance, referred to as the shunt resistance $\left(\mathrm{R}_{\mathrm{sh}}\right)^{44}$. Since there are two parallel processes inflicting $\mathrm{R}_{2}$ and some of the points are lying in the transition region between these process $(0.4$ to $0.7 \mathrm{~V})$, it is not possible to correctly estimate the value of $R_{s h}$. For $V_{o c}>0.7 V, R_{2}$ decreases exponentially with voltage and light intensity, following the equation 1 , indicating that $\mathrm{R}_{2}$ at such voltages is also related with the non-radiative recombination process ${ }^{43,44}$. Our previous studies suggest that, the recombination resistance $\left(\mathrm{R}_{\mathrm{rec}}\right)$ of PSCs is the addition of both resistances $\left(R_{\text {rec }}=R_{1}+R_{2}\right)^{36}$. Figure $3 E$ shows the $R_{\text {rec }}$ in the region of voltages where the recombination process is dominant for both resistances. It is possible to observe that both samples are having almost the same slope. A very useful parameter to describe the recombination process in solar cell is the ideality factor (m) ${ }^{43,44}$. From this parameter, it is possible to determine the origin of the recombination, being a band to band recombination (bulk recombination), when $\mathrm{m}=1$ and band to defect recombination (which in the case of PSC has been ascribed to as surface recombination) $)^{36,42,44}$ when $\mathrm{m}=2$. Using equation 1 , the ideality factor was calculated, and was found to be, $\mathrm{m}=2.14 \pm 0.17$ for $\mathrm{AD}$ and $2.21 \pm 0.14$ for AAD process. It indicates that the surface recombination is the dominant process in both kinds of cells. 
However, AAD samples (S2) have slightly higher $\mathrm{R}_{0}$ than the AD samples, indicating that recombination process is reduced with the AAD method. As per the literature, this recombination process occurs due to the accumulation of holes at the $\mathrm{TiO}_{2} /$ perovskite interface. ${ }^{36}$ One recurrent hypothesis is that, these holes accumulate at trap levels produced by movable defects like interstitial iodine $e^{44,46-50}$ in perovskite devices. It is considered as one of the most important source defects at the grain boundaries ${ }^{44,50}$. Then, it can be presumed that, the improvement in morphology induced by the AAD process reduces the number of movable defects, resulting in the observed reduction of recombination process. Other approaches propose the formation of a valence band hole accumulation zone. ${ }^{36,42}$

This increase in recombination resistance can also be described as a shift of $\mathrm{R}_{\mathrm{rec}}$ to higher voltages, which corresponds to a shift in the Fermi level of $38 \mathrm{mV}$. This value perfectly matches with the increase in $\mathrm{V}_{\mathrm{oc}}$ observed in the $\mathrm{J}-\mathrm{V}$ curves. However, as previously stated by Garcia-Belmonte et al., the voltage offset $\left(\Delta \mathrm{V}_{\mathrm{oc}}\right)$ observed in both $\mathrm{J}-\mathrm{V}$ and $\mathrm{R}_{2}$ curves is due to an energetic $\left(\Delta \mathrm{V}_{\mathrm{E}}\right)$ and a kinetic $\left(\Delta \mathrm{V}_{\text {kin }}\right)$ voltage $\operatorname{shift}^{30}$.

$$
\Delta \mathrm{V}_{\mathrm{oc}}=\Delta \mathrm{V}_{\mathrm{E}}+\Delta \mathrm{V}_{\text {kin }}
$$

Absorption data indicates that $\Delta \mathrm{E}_{\mathrm{g}}=0 \mathrm{eV}$, which indicates that the increase in $\mathrm{V}_{\mathrm{oc}}$ is exclusively caused by the reduction in the recombination process. This is corroborated by the fact that $\Delta \mathrm{V}_{\mathrm{oc}}=38 \mathrm{mV}$ exactly matches the shift in $\mathrm{R}_{\text {rec }}$ as observed in Fig. 3D

$J$-V modeling. To have a complete understanding of the variation of shunt and series resistances and their effect on the performance of PSC with respect to the AAD process, the 
$\mathrm{J}-\mathrm{V}$ curves were fitted using a simple model, considering the photogenerated current $\left(\mathrm{J}_{\mathrm{ph}}\right)$, recombination current $\left(\mathrm{J}_{\mathrm{rec}}\right)$, and shunt current $\left(\mathrm{J}_{\mathrm{sh}}\right)^{36,43}$.

$$
\begin{gathered}
\mathrm{J}=\mathrm{J}_{\mathrm{ph}}-\mathrm{J}_{\text {rec }}-\mathrm{J}_{\mathrm{sh}} \\
\mathrm{J}=\mathrm{J}_{\mathrm{ph}}-\frac{2 \mathrm{k}_{\mathrm{B}} / \mathrm{q}}{\mathrm{R}_{\mathrm{rec}}}-\frac{\mathrm{V}_{\mathrm{f}}}{\mathrm{R}_{\mathrm{sh}}}
\end{gathered}
$$

where $R_{\text {rec }}$ is estimated from the impedance analysis, $R_{\text {sh }}$ is the shunt resistance, calculated from the fitting, and $\mathrm{V}_{\mathrm{f}}$ is the applied voltage $\left(\mathrm{V}_{\mathrm{app}}\right)$ corrected with the voltage drop due to series resistance $\left(\mathrm{R}_{\mathrm{s}}\right)^{44}$.

$$
\mathrm{V}_{\mathrm{f}}=\mathrm{V}_{\mathrm{App}^{-}}-\mathrm{JR}_{\mathrm{s}}
$$

The resulting curves are shown in Figure 2B. The model reproduces the J-V curve behavior of both kind of samples with almost accuracy, confirming that $R_{\text {rec }}$ is the addition of the high and low-frequency resistance.

According to the fitting results shown in Table $2, R_{s}$ is $\sim 3 \Omega \mathrm{cm}^{2}$. It indicates that the resistance from contacts and charge carrier transport within the cells are very small giving high PV performance, as reported previously ${ }^{44}$. Additionally, the $\mathrm{R}_{\mathrm{s}}$ related with transport resistance at contacts and wires is not modified by the use of AAD method as it can be expected. The $\mathrm{R}_{\mathrm{rec}}$, as previously mentioned, has a small increase of $\sim 170 \Omega \mathrm{cm}^{2}$ at $\mathrm{V}=0.7 \mathrm{~V}$ which could be attributed to the reduction of grain boundaries. In addition, the $\mathrm{R}_{\mathrm{sh}}$ of AAD samples is 7 times higher than the one obtained by $\mathrm{AD}$ (from 0.5 to $3.5 \mathrm{~K} \Omega \mathrm{cm}^{2}$ ). As this resistance is related to the leakage processes, this increase indicates the improvement in film quality obtained by AAD process reducing the pinholes and other short-circuit sources resulting in the mentioned $\mathrm{FF}$ enhancement. 
Under open-circuit condition, the photogenerated current $\mathbf{J}_{\mathrm{ph}}$ is completely suppressed by $J_{\text {rec }}$ and $J_{\text {sh }}\left(J_{\mathrm{ph}}=J_{\mathrm{rec}(\mathrm{oc})}+\mathrm{J}_{\mathrm{sh}(\mathrm{oc})}\right)$. Then, it is possible to estimate the $\mathrm{J}_{\mathrm{ph}}$ and compare it with the measured $\mathbf{J}_{\mathrm{sc}}$. From the Table 2, it is observed that the AAD process effectively increases the $\mathrm{J}_{\mathrm{ph}}$ from 20.0 to $21.8 \mathrm{~mA} / \mathrm{cm}^{2}$ which means an increase of $9 \%$ in the photogeneration. Such increment is in agreement with the IPCE and absorption increment discussed above. Under short-circuit conditions, a part of the photogenerated carriers recombines at the outer interface, while the main parts of the carriers are drained off. This implies that the measured short-circuit current is reduced by a term related to the carrier loss expressed by ${ }^{36}$.

$$
\mathrm{J}_{\mathrm{sc}}=\mathrm{J}_{\mathrm{ph}}-\mathrm{J}_{\mathrm{rec}(\mathrm{sc})}
$$

The ratio between the recombination current and the photogenerated current gives the effective collection loss of the solar cell,

$$
\begin{gathered}
\alpha=\frac{\mathrm{J}_{\mathrm{rec}(\mathrm{sc})}}{\mathrm{J}_{\mathrm{ph}}}=\frac{\mathrm{J}_{\mathrm{rec}(\mathrm{sc})}}{\mathrm{J}_{\mathrm{rec}(\mathrm{oc})}+\mathrm{J}_{\mathrm{sh}(\mathrm{oc})}} \\
\alpha=1-\frac{\mathrm{J}_{\mathrm{sc}}}{\mathrm{J}_{\mathrm{ph}}}
\end{gathered}
$$

This parameter will determine the difference between internal and external quantum efficiency. As observed in Table 2, the collection loss for AD and AAD samples are below $1 \%$ being a little lower for AAD samples, indicating that both samples are having very good charge extraction at the contacts. 
Table 2: Calculated values of the photogenerated current and the resistances obtained from the $\mathrm{J}-\mathrm{V}$ curve fitting

\begin{tabular}{|c|c|c|c|c|c|c|}
\hline Sample & $\begin{array}{c}\mathrm{R}_{\mathrm{s}} \\
\mathrm{Ocm}^{2}\end{array}$ & $\begin{array}{c}\mathrm{R}_{\mathrm{rec}} \\
(\mathrm{V}=0.7 \mathrm{~V})\end{array}$ & $\begin{array}{c}\mathrm{R}_{\mathrm{sh}} \\
\mathrm{KO} \mathrm{cm}^{2}\end{array}$ & $\begin{array}{c}\mathrm{J}_{\mathrm{ph}} \\
\mathrm{mA} / \mathrm{cm}^{2}\end{array}$ & $\begin{array}{c}\alpha \\
(\%)\end{array}$ & $1-\alpha$ \\
\hline $\mathrm{AD}$ & 2.9 & 316 & 0.5 & 20.0 & 0.7 & 0.993 \\
\hline AAD & 2.9 & 492 & 3.5 & 21.8 & 0.1 & 0.999 \\
\hline
\end{tabular}

According to the experimental evidence described above, it is possible to conclude that, when $\mathrm{AD}$ samples are under light conditions, see Figure 4A, electron-hole pairs are photogenerated inside $\mathrm{MAPbI}_{3}$ bulk (blue arrow). The holes move towards the spiroOMeTAD (HTM, hole transporting material) which is further transported to the metallic contact. While, the electrons move towards the $\mathrm{TiO}_{2}$ electrode, presumably following tunneling injection, where it will be given to the FTO, thus generating the current. However, PSCs have ionic defects like interstitial I' that easily move under working conditions and accumulate at the $\mathrm{TiO}_{2}$ /perovskite interface as a self-doping effect. These ions introduce trap levels near the valence band, where photogenerated holes accumulate favoring the recombination (red arrows). Additionally, some electrons leak in as shunt current (orange arrow) due to the imperfections of the perovskite films (like pin holes). When AAD method is employed, see Figure4B, a considerable increase in the grain size is observed. As a consequence, the light absorption cross-section is increased resulting in an increase in the photogeneration directly improving the $\mathrm{J}_{\mathrm{sc}}$. Another consequence of the increase in crystal size 
is the reduction of grain boundaries which act as the principal source of mobile defects. Then, the recombination is reduced at the outer interfaces resulting in a higher capability of accumulating electrons at the conduction band leading to an upshifting of the electron quasi-fermi level and thus increasing the $\mathrm{V}_{\mathrm{oc}}$. Finally, the improvement in the perovskite film quality results in a reduction of leakage sources leading to an increase in the FF. In this way, the AAD process improves the three photovoltaic parameters at the same time, resulting in a considerable enhancement in the photo conversion efficiency.

(A)

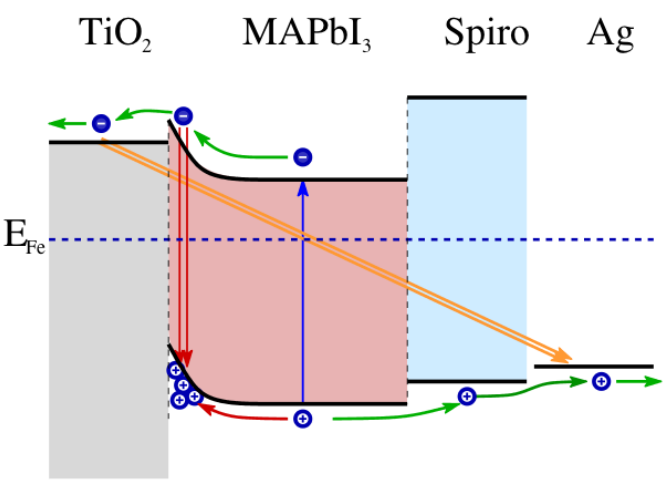

(B)

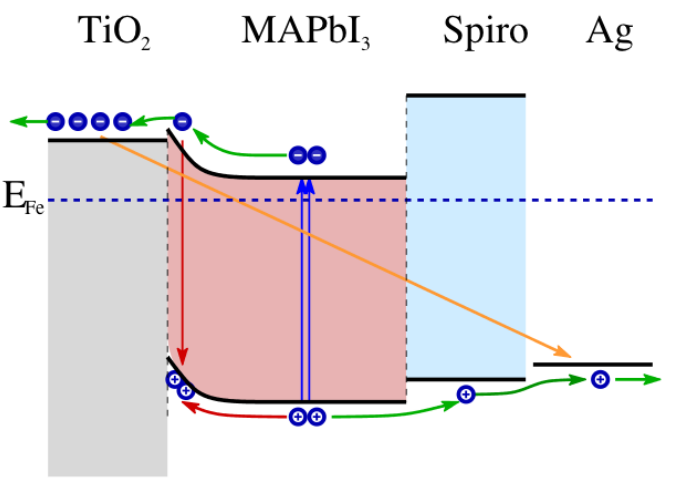

Fig 4 Illustrative energy diagram of PSC made by A) AD process and B) AAD process, showing the electron and hole flux for: extracted current $\mathbf{J}$ (green arrows), photogenerated currents $\mathrm{J}_{\mathrm{ph}}$ (blue arrows), nonradiative recombination current $\mathrm{J}_{\mathrm{rec}}$ (red arrows), and shortcircuit currents $\mathbf{J}_{\mathrm{sh}}$ (orange arrows).

As conclusion, the photovoltaic properties of $\mathrm{MAPbI}_{3}$ solar cells deposited by antisolvent (AD) and air extraction anti-solvent method (AAD) were systematically studied. It was found that the samples made by AAD process have higher $\mathrm{J}_{\mathrm{sc}}, \mathrm{V}_{\mathrm{oc}}$, and FF. Impedance analysis and $\mathrm{J}-\mathrm{V}$ curve fitting were performed to elucidate the physical mechanism within the device. The studies indicate that the improved morphology and enhanced crystallinity obtained by the AAD method induces higher absorption, resulting in an increase in $\mathrm{J}_{\mathrm{sc}}$ from 
19.8 to $21.7 \mathrm{~mA} / \mathrm{cm}^{2}$. At the same time, it reduces the recombination centers arising from the grain boundaries, resulting in a small increase of $\mathrm{V}_{\mathrm{oc}}$ from 0.957 to $0.995 \mathrm{~V}$. Finally, electron leakage is reduced, which results in an increase in FF from 66.7 to $72.6 \%$ These three effects, result in an enhancement of PCE from 12.7 to $15.7 \%$. This work also highlights the importance of impedance spectroscopy in understanding the relationship between the deposition methods and the obtained morphology on the final cell performance.

\section{Experimental Section}

Perovskite film fabrication. $\mathrm{CH}_{3} \mathrm{NH}_{3} \mathrm{I}$ (Dyesol), $\mathrm{PbI}_{2}(99.99 \%$, Lumtec) and dimethyl sulfoxide (DMSO) (> 99.9\%, Sigma-Aldrich) were dissolved in $1 \mathrm{~mL}$ of anhydrous N, $\mathrm{N}$-dimethylformamide (DMF) (>99\%, Sigma-Aldrich) at $80^{\circ} \mathrm{C}$ for $2 \mathrm{~h}$ to prepare the perovskite solution. In the anti-solvent deposition approach (AD), $100 \mu \mathrm{L}$ of the perovskite solution was spin coated on mesoporous $\mathrm{TiO}_{2}$ at $5000 \mathrm{rpm}$ for $40 \mathrm{~s}$. During the spin coating process, $0.5 \mathrm{~mL}$ of ethoxyethane (95\%, Sigma-Aldrich) was dropped instantaneously at the center of the substrate. The deposition resulted in a transparent film which was transferred onto a hotplate and heated at $100^{\circ} \mathrm{C}$ for $3 \mathrm{~min}$. In the AAD approach ${ }^{38}$, exactly the same procedure was followed but the whole process was executed under the intake of an airextractor hood whose operation started a few seconds before the start of the spin coating process and was kept on until the end of the process.

\section{ACKNOWLEDGMENTS}


We acknowledge financial support from CONACYT through grant 259192 and the CEMIE- Solar (207450) consortium projects P27 and P28. From MINECO of Spain under Projects MAT201676892-C3-1-R, and Generalitat Valenciana Project PROMETEOII/2014/020. S. Sidhik acknowledge the doctoral fellowship from SENER-CONACYT and thanks Maria Christian Albor for SEM analysis.

Supporting Information. Detailed experimental methodology, photovoltaic metrics of 15 devices 


\section{References}

(1) Park, N.-G. Organometal Perovskite Light Absorbers Toward a 20\% Efficiency Low-Cost SolidState Mesoscopic Solar Cell. The Journal of Physical Chemistry Letters. 2013, 4 (15), 2423-2429.

(2) Snaith, H. J. Perovskites: the Emergence of a New Era for Low-Cost, High-Efficiency Solar Cells. The Journal of Physical Chemistry Letters. 2013, 4 (21), 3623-3630.

(3) Jeon, N. J.; Noh, J. H.; Kim, Y. C.; Yang, W. S.; Ryu, S.; Seok, S. I. Solvent Engineering for HighPerformance Inorganic-Organic Hybrid Perovskite Solar Cells. Nature Mater.2014, 13 (9), 897903.

(4) Green, M. A.; Emery, K.; Hishikawa, Y.; Warta, W.; Dunlop, E. D. Solar Cell Efficiency Tables (Version 45). Prog.Photovolt: Res. Appl. 2015, 23 (1), 1-9.

(5) Saliba, M.; Matsui, T.; Seo, J.-Y.; Domanski, K.; Correa-Baena, J.-P.; Nazeeruddin, M. K.; Zakeeruddin, S. M.; Tress, W.; Abate, A.; Hagfeldt, A.; et al. Cesium-Containing Triple CationPerovskite Solar Cells: Improved Stability, Reproducibility and High Efficiency. Energy Environ. Sci. 2016, 9 (6), 1989-1997.

(6) Li, X.; Bi, D.; Yi, C.; Decoppet, J. D.; Luo, J.; Zakeeruddin, S. M.; Hagfeldt, A.; Grätzel, M. A Vacuum Flash-Assisted Solution Process for High-Efficiency Large-Area Perovskite Solar Cells.Scince. 2016, 353 (6294), 58-62.

(7) Xing, G., Mathews, N., Lim, S. S., Yantara, N., Liu, X., Sabba, D., ...\& Sum, T. C. (2014). Lowtemperature solution-processed wavelength-tunable perovskites for lasing.Nature materials, 13(5), 476.

(8) Suárez, I.; Juarez-Perez, E. J.; Bisquert, J.; Mora-Sero, I.; Martínez Pastor, J. P. Polymer/Perovskite Amplifying Waveguides for Active Hybrid Silicon Photonics. Adv. Mater. 2015, 27 (40), 61576162.

(9) Stranks, S. D.; Eperon, G. E.; Grancini, G.; Menelaou, C.; Alcocer, M. J. P.; Leijtens, T.; Herz, L. M.; Petrozza, A.; Snaith, H. J. Electron-Hole Diffusion Lengths Exceeding 1 Micrometer in an OrganometalTrihalide Perovskite Absorber. Scince. 2013, 342 (6156), 341-344.

(10) Tian, W.; Zhao, C.; Leng, J.; Cui, R.; Jin, S. Visualizing Carrier Diffusion in Individual SingleCrystal Organolead Halide Perovskite Nanowires and Nanoplates. J. Am. Chem. Soc. 2015, 137 (39), $12458-12461$.

(11) Oga, H.; Saeki, A.; Ogomi, Y.; Hayase, S.; Seki, S. Improved Understanding of the Electronic and Energetic Landscapes of Perovskite Solar Cells: High Local Charge Carrier Mobility, Reduced Recombination, and Extremely Shallow Traps. J. Am. Chem. Soc. 2014, 136 (39), 13818-13825.

(12) Wehrenfennig, C.; Eperon, G. E.; Johnston, M. B.; Snaith, H. J.; Herz, L. M. High Charge Carrier Mobilities and Lifetimes in OrganoleadTrihalide Perovskites. Adv. Mater. 2013, 26 (10), 1584-1589. 
(13) Ahn, N., Son, D. Y., Jang, I. H., Kang, S. M., Choi, M., \& Park, N. G. Highly reproducible perovskite solar cells with average efficiency of $18.3 \%$ and best efficiency of $19.7 \%$ fabricated via Lewis base adduct of lead (II) iodide. Journal of the American Chemical Society. 2015, 137(27), 86968699 .

(14) Sidhik, S., Esparza, D., López-Luke, T., \& De la Rosa, E. Study of ethoxyethane deposition time and Co (III) complex doping on the performance of mesoscopic perovskite based solar cells. Solar Energy Materials and Solar Cells. 2017, 163, 224-230.

(15) Yang, W. S., Park, B. W., Jung, E. H., Jeon, N. J., Kim, Y. C., Lee, D. U., \&Seok, S. I. Iodide management in formamidinium-lead-halide-based perovskite layers for efficient solar cells. Science. 2017, 356(6345), 1376-1379.

(16) Jeon, N. J., Noh, J. H., Kim, Y. C., Yang, W. S., Ryu, S., \&Seok, S. I. Solvent engineering for highperformance inorganic-organic hybrid perovskite solar cells. Nature materials. 2014,13(9), 897903.

(17) Kedem, N., Brenner, T. M., Kulbak, M., Schaefer, N., Levcenko, S., Levine, I., \&Cahen, D. Lightinduced increase of electron diffusion length in ap-n junction type $\mathrm{CH}_{3} \mathrm{NH}_{3} \mathrm{PbBr}_{3}$ perovskite solar cell. The journal of physical chemistry letters, 2015, 6(13), 2469-2476.

(18) Yu, H., Wang, F., Xie, F., Li, W., Chen, J., \& Zhao, N. The Role of Chlorine in the Formation Process of “CH3NH3PbI3-xClx"Perovskite.Advanced Functional Materials. 2014, 24(45), 7102-7108.

(19) Saliba, M., Matsui, T., Seo, J. Y., Domanski, K., Correa-Baena, J. P., Nazeeruddin, M. K., \&Grätzel, M. Cesium-containing triple cation perovskite solar cells: improved stability, reproducibility and high efficiency. Energy \& environmental science. 2016, 9(6), 1989-1997.

(20) Saliba, M., Matsui, T., Domanski, K., Seo, J. Y., Ummadisingu, A., Zakeeruddin, S. M., \&Grätzel, M. Incorporation of rubidium cations into perovskite solar cells improves photovoltaic performance. Science. 2016, 354(6309), 206-209.

(21) Mei, A., Li, X., Liu, L., Ku, Z., Liu, T., Rong, Y., \&Grätzel, M. A hole-conductor-free, fully printable mesoscopic perovskite solar cell with high stability.Science. 2014, 345(6194), 295-298.

(22) Zhu, W., Bao, C., Wang, Y., Li, F., Zhou, X., Yang, J., \&Zou, Z. Coarsening of one-step deposited organoleadtriiodide perovskite films via Ostwald ripening for high efficiency planar-heterojunction solar cells. Dalton Transactions. 2016, 45(18), 7856-7865.

(23) Wu, C. G., Chiang, C. H., Tseng, Z. L., Nazeeruddin, M. K., Hagfeldt, A., \&Grätzel, M. High efficiency stable inverted perovskite solar cells without current hysteresis. Energy \& Environmental Science. 2015, 8(9), 2725-2733.

(24) Yantara, N., Sabba, D., Yanan, F., Kadro, J. M., Moehl, T., Boix, P. P., \&Grätzel, C. Loading of mesoporoustitania films by $\mathrm{CH}_{3} \mathrm{NH}_{3} \mathrm{PbI}_{3}$ perovskite, single step vs. sequential deposition. Chemical Communications. 2015, 51(22), 4603-4606. 
(25) Ip, A. H., Quan, L. N., Adachi, M. M., McDowell, J. J., Xu, J., Kim, D. H., \& Sargent, E. H. A twostep route to planar perovskite cells exhibiting reduced hysteresis. Applied Physics Letters. 2015, 106(14), 143902.

(26) Zheng, X., Chen, B., Wu, C., \&Priya, S. Room temperature fabrication of $\mathrm{CH}_{3} \mathrm{NH}_{3} \mathrm{PbBr}_{3}$ by antisolvent assisted crystallization approach for perovskite solar cells with fast response and small $\mathrm{J}-\mathrm{V}$ hysteresis. Nano Energy. 2015, 17, 269-278.

(27) Li, X., Bi, D., Yi, C., Décoppet, J. D., Luo, J., Zakeeruddin, S. M., \&Grätzel, M. A vacuum flashassisted solution process for high-efficiency large-area perovskite solar cells.Science. 2016, 353(6294), 58-62.

(28 Zhou, Y., Yang, M., Wu, W., Vasiliev, A. L., Zhu, K., \&Padture, N. P. (2015). Room-temperature crystallization of hybrid-perovskite thin films via solvent-solvent extraction for high-performance solar cells.Journal of Materials Chemistry A. 2015, 3(15), 8178-8184

(29) Fabregat-Santiago, F., Bisquert, J., Garcia-Belmonte, G., Boschloo, G., \&Hagfeldt, A. Influence of electrolyte in transport and recombination in dye-sensitized solar cells studied by impedance spectroscopy. Solar Energy Materials and Solar Cells. 2005, 87(1), 117-131.

(30) Garcia-Belmonte, G.; Guerrero, A.; Bisquert, J. Elucidating Operating Modes of BulkHeterojunction Solar Cells From Impedance Spectroscopy Analysis. The Journal of Physical Chemistry Letters. 2013, 4 (6), 877-886.

(31) Mora-Sero, I.; Giménez, S.; Fabregat-Santiago, F.; Gomez, R.; Shen, Q.; Toyoda, T.; Bisquert, J. Recombination in Quantum Dot Sensitized Solar Cells. Acc. Chem. Res. 2009, 42 (11), 1848-1857.

(32) Dualeh, A.; Moehl, T.; Tétreault, N.; Teuscher, J.; Gao, P.; Nazeeruddin, M. K.; Grätzel, M. Impedance Spectroscopic Analysis of Lead Iodide Perovskite-Sensitized Solid-State Solar Cells. ACS Nano. 2014, 8 (1), 362-373.

(33) González-Pedro, V.; Juarez-Perez, E. J.; Arsyad, W.-S.; Barea, E. M.; Fabregat-Santiago, F.; MoraSero, I.; Bisquert, J. General Working Principles of $\mathrm{CH}_{3} \mathrm{NH}_{3} \mathrm{PbX}_{3}$ Perovskite Solar Cells. Nano.Lett. 2014, 14 (2), 888-893.

(34) Pascoe, A. R.; Duffy, N. W.; Scully, A. D.; Huang, F.; Cheng, Y.-B. Insights Into Planar $\mathrm{CH}_{3} \mathrm{NH}$ ${ }_{3} \mathrm{PbI}_{3}$ Perovskite Solar Cells Using Impedance Spectroscopy.J. Phys. Chem. C. 2015, 119 (9), 44444453.

(35) Pockett, A.; Eperon, G. E.; Peltola, T.; Snaith, H. J.; Walker, A.; Peter, L. M.; Cameron, P. J. Characterization of Planar Lead Halide Perovskite Solar Cells by Impedance Spectroscopy, Open-Circuit Photovoltage Decay, and Intensity-Modulated Photovoltage/Photocurrent Spectroscopy. J. Phys. Chem. C 2015, 119 (7), 3456-3465.

(36) Zarazúa, I.; Han, G.; Boix, P. P.; Mhaisalkar, S.; Fabregat-Santiago, F.; Mora-Sero, I.; Bisquert, J.; Garcia-Belmonte, G. Surface Recombination and Collection Efficiency in Perovskite Solar Cells From Impedance Analysis. The Journal of Physical Chemistry Letters. 2016, 5105-5113. 
(37) Almora, O.; Zarazúa, I.; Mas-Marza, E.; Mora-Sero, I.; Bisquert, J.; Garcia-Belmonte, G. Capacitive Dark Currents, Hysteresis, and Electrode Polarization in Lead Halide Perovskite Solar Cells. The Journal of Physical Chemistry Letters. 2015, 6, 1645-2652.

(38) Sidhik, S., Esparza, D., Martínez-Benítez, A., López-Luke, T., Carriles, R., \& De la Rosa, E. Improved performance of mesoscopic perovskite solar cell using an accelerated crystalline formation method. Journal of Power Sources. 2017, 365, 169-178.

(39) Q.; Li, G. R.; Song, J.; Zhao, Y.; Qiang, Y.; Gao, X. P. Improving the Photovoltaic Performance of Perovskite Solar Cells with Acetate. Sci. Rep. 2016, 6 (1), 344.

(40) Ugur, E.; Sheikh, A. D.; Munir, R.; Khan, J. I.; Barrit, D.; Amassian, A.; Laquai, F. Improved Morphology and Efficiency of N-I-P Planar Perovskite Solar Cells by Processing with Glycol Ether Additives. ACS Energy Lett .2017, 2 (9), 1960-1968.

(41) Li, X.; Bi, D.; Yi, C.; Decoppet, J. D.; Luo, J.; Zakeeruddin, S. M.; Hagfeldt, A.; Grätzel, M. A Vacuum Flash-Assisted Solution Process for High-Efficiency Large-Area Perovskite Solar Cells.Scince 2016, 353 (6294), 58-62.]

(42) Zarazúa, I.; Bisquert, J.; Garcia-Belmonte, G. Light-Induced Space-Charge Accumulation Zone as Photovoltaic Mechanism in Perovskite Solar Cells. The Journal of Physical Chemistry Letters 2016, $525-528$.

(43) Correa-Baena, J.-P.; Turren-Cruz, S.-H.; Tress, W.; Hagfeldt, A.; Aranda, C.; Shooshtari, L.; Bisquert, J.; Guerrero, A. Changes From Bulk to Surface Recombination Mechanisms Between Pristine and Cycled Perovskite Solar Cells. ACS Energy Lett. 2017, acsenergylett.7b00059.

(44) Park, N.-G.; Grätzel, M.; Miyasaka, T. Organic-Inorganic Halide Perovskite Photovoltaics: From Fundamentals to Device Architectures; Springer: Cham, 2016.

(45) Zarazúa, I.; Esparza, D.; Lopez-Luke, T.; Ceja-Fdez, A.; Reyes-Gomez, J.; Mora-Seró, I.; La Rosa, De, E. Effect of the electrophoretic deposition of Au NPs in the performance CdS QDs sensitized solar Cells Electrochimica Acta. Electrochimicaacta 2016, 188, 710-717.

(46) Wetzelaer, G.-J. A. H.; Scheepers, M.; Sempere, A. M.; Momblona, C.; vila, J.; Bolink, H. J. TrapAssisted Non-Radiative Recombination in Organic-Inorganic Perovskite Solar Cells. Adv. Mater. 2015, 27 (11), 1837-1841.

(47 Yin, W. J., Shi, T., \& Yan, Y. Unusual defect physics in $\mathrm{CH}_{3} \mathrm{NH}_{3} \mathrm{PbI}_{3}$ perovskite solar cell absorber. Applied Physics Letters. 2014, 104(6), 063903.

(48) Yin, W.-J.; Shi, T.; Yan, Y. Unique Properties of Halide Perovskites as Possible Origins of the Superior Solar Cell Performance. Adv. Mater. 2014, 26 (27), 4653-4658.

(49) Yang, T. Y., Gregori, G., Pellet, N., Grätzel, M., \& Maier, J. The significance of ion conduction in a hybrid organic-inorganic lead-iodide-based perovskite photosensitizer. Angewandte Chemie. 2015, 127(27), 8016-8021. 
(50) Deng, Y.; Xiao, Z.; Huang, J. LightInduced Self-Poling Effect on OrganometalTrihalide Perovskite Solar Cells for Increased Device Efficiency and Stability. Adv. Energy Mater.2015, 5 (20). 